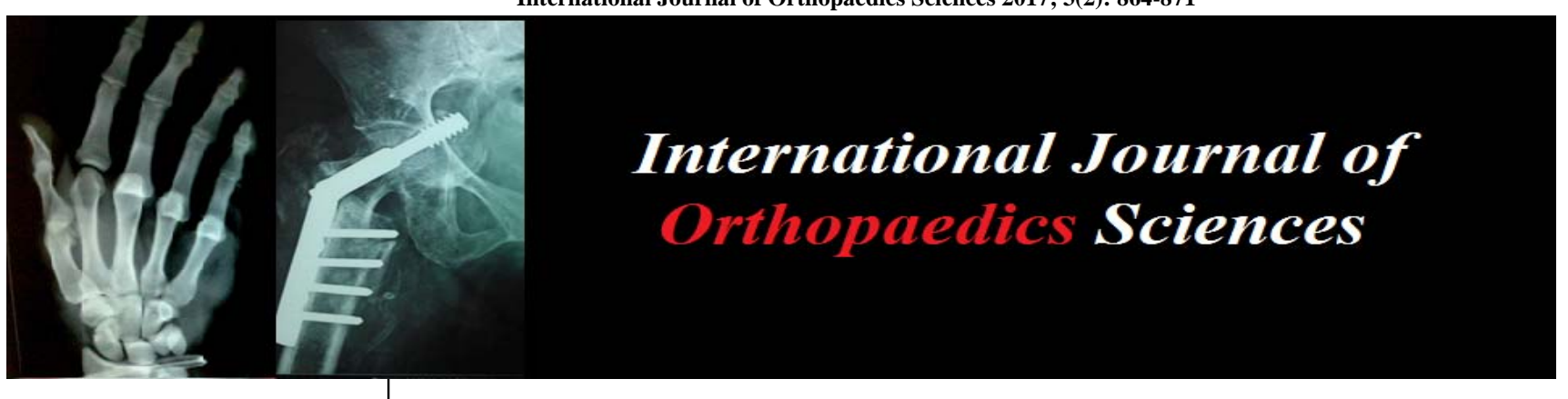

ISSN: $2395-1958$

IJOS 2017; 3(2): 864-871

(C) 2017 IJOS

www.orthopaper.com

Received: 03-02-2017

Accepted: 04-03-2017

\section{Muralidhar BM}

Associate Professor, Department

of Orthopaedics, Sri Siddhartha

Medical College, Siddhartha

Academy of Higher Education

University, Tumkur, Karnataka,

India

\section{Madhusudan H}

Junior Resident, Department of Orthopaedics, Sri Siddhartha

Medical College, Siddhartha

Academy of Higher Education

University, Tumkur, Karnataka, India

Mithun Mohan

Junior Resident, Department of Orthopaedics, Sri Siddhartha Medical College, Siddhartha Academy of Higher Education University, Tumkur, Karnataka, India
Correspondence Muralidhar BM

Associate Professor, Department of Orthopaedics, Sri Siddhartha Medical College, Siddhartha Academy of Higher Education University, Tumkur, Karnataka, India

\section{Study of patellar fractures treated by modified tension band wiring-A prospective study}

\author{
Muralidhar BM, Madhusudan $\mathrm{H}$ and Mithun Mohan
}

DOI: http://dx.doi.org/10.22271/ortho.2017.v3.i2j.93

Abstract

Background and objectives: Patellar fractures are common and it constitutes about $1 \%$ of all skeletal injuries resulting from either direct or indirect trauma. Patella is of importance for the extension of knee joint, which increases the force of quadriceps apparatus by improving the leverage.

This study directed towards the functional results and complications of modified tension band wiring for patella fractures.

Materials and methods: This prospective study is done in Department of Orthopaedics at Sri Siddhartha medical college, hospital and Research Center Tumkur during the period from September 2015 and February 2017. This study consists of 20 cases of displaced transverse fracture patella treated by modified tension band wiring.

Results: In this study, average age was of 39.7 with male patients outnumbered the females by more than double, Right sided patellar fractures were predominant, $70 \%$ of our patients had no pain or only mild pain. Only $20 \%$ of our patients had significant extensor lag and nearly $80 \%$ had normal quadriceps strength. We had $70 \%$ excellent and $20 \%$ good and $10 \%$ poor results according to modified scale of bostman et al.

Conclusion: Our study shows that modified tension band wiring is a definitive procedure in management of displaced transverse patellar fracture with least complications. This surgery of modified tension band wiring helps for early mobilization post-operatively which plays an important role in final outcome. Early and continuous physiotherapy following surgery is a paramount importance in determining the end results.

Keywords: Modified tension band wiring, fracture patella, knee joint

\section{Introduction}

The patella is the largest sesamoid bone in the human body situated in front of knee in the tendon quadriceps femoris muscles. It is flattened, triangular distally and curved proximally with the thickness between $1.5 \mathrm{~cm}$ and $2 \mathrm{~cm}^{[1]}$.

The patella is of importance for the extension of knee joint. It increases the force of the quadriceps apparatus by improving the leverage. In addition, it protects the anterior articular surface of distal femur against external violence.

Fractures of the patella constitute almost $1 \%$ of all skeletal injuries, resulting from either direct or indirect trauma ${ }^{[2]}$.

Most are transverse fractures involving the middle third of the patella in patients aged 20 and $50 y r$, and affect almost twice as many men as women

Thomson in 1935 treated patellar fractures by surgical excision of small fragments and capsule repair. He suggested avoiding total patellectomy, because of the impairment of leverage of quadriceps during extension of knee ${ }^{[3]}$.

Brookes and heygrooves in 1937 suggested that the patella inhibits the action of quadriceps tendon and they thought that the strength of the knee was improved with patellectomy ${ }^{[4,5]}$.

Haxton in 1945 on the basis of his experiments proved that patella improves the efficiency of the knee joint and demonstrated that the power of extension increases as the knee joint extends [6].

Cohn in 1944, found degenerative changes in patellectomised rabbits and concluded that procedure should avoided inhuman patients ${ }^{[7]}$. 
Scott in 1949 did clinical study of total patellectomy and reported increased incidence of pain and discomfort during movement of the knee ${ }^{[8]}$.

$\mathrm{O}$ donoghue suggested that total patellectomy diminished the extensor power of the knee and resulted in various post patellectomy symptoms ${ }^{[9]}$.

Muller in 1970 introduced anterior application of two stainless steel wires inserted through longitudinally drilled holes ${ }^{[10]}$.

Marten. H.G. Heusinkveld ${ }^{11}$ et al study shows pain and irritation were most commonly present following this modality of treatment. Skin irritation, wire migration or Kwire loosening were observed.

Modified tension band technique is currently the most widely accepted and several studies have shown a high percentage of good results. Several methods of internal fixation of fractured patella have been advocated. This dissertation is directed towards the clinical evaluation of patella fractures treated with modified tension band wiring.

\section{Methods}

The study was conducted in Sri Siddhartha Medical College, Tumkur from September 2015 and February 2017. This study consists of 20 cases of displaced transverse fracture patella treated by modified tension band wiring. The cases were selected based on inclusion and exclusion criteria

\section{Aims and objectives}

Aim of the study

To evaluate the clinical and functional outcome of modified tension band wiring for fractures of patella.

\section{Objectives}

To assess the functional results of modified tension band wiring in patellar fractures.

- To assess the complications of modified tension band wiring in patellar fractures.

\section{Inclusion criteria}

1. All closed and type 1open displaced transverse patellar fractures.

2. Age $>16$ years $<60$ yrs.

3. Sex: both male and female

4. Patient who are medically fit for the surgery

\section{Exclusion criteria}

1. Type II and type III compound fractures

2. Grossly comminuted, vertical or marginal fractures.

3. Old fractures (more than 2-3 weeks).

4. Undisplaced transverse fractures.

\section{Methods used in the study}

A prospective study comprising of patients identified for surgical treatment of transverse fracture of patella admitted to Sri Siddhartha Medical College

All patients in the study after undergoing routine clinical examination would be subjected to following battery of investigations complete haemogram with ESR Chest X ray PA view

Electrocardiogram

2D echocardiogram

Once the patient is admitted to the hospital, the details of the cases were recorded including name, age, sex, occupation, address detailed clinical history, past history, family and personal history clinical history will be taken. Thorough general and clinical examination will be carried out. Routine blood investigation and Radiological investigations will be done.

The limb will be immobilized by an above knee plaster of Paris posterior slab.

Patients will be explained in detail about surgery, possible complications and limitations to be followed after surgery.

\section{Operative procedure}

The fracture site will be exposed through transverse incision/ midline longitudinal incision in front of the knee; the fragments will be reduced and held in position with the help of patellar clamp or towel clips. Two Kirschner wires of 2 $\mathrm{mm}$ thickness are passed parallel to each other from above down wards starting at its superior border till lower pole of patella is reached. $18 \mathrm{G}$ stainless steel wire is taken and passed deep to ligamentum patellae inferiorly and behind the quadriceps tendon superiorly making a figure of " 8 " in front of the patella sufficient tension is given. Tear in the quadriceps expansion is sutured with vicryl and wound closed in layers. Above Knee slab or pressure bandage is given as a temporary immobilization. Check X-Rays are done post operatively. The operated knee will immobilized in extension in an above knee posterior slab, and will be advised to do straight leg raising and weight bearing from third postoperative day. Sutures will be removed from $12^{\text {th }}$ to $14^{\text {th }}$ day and knee flexion exercise will be started with quadriceps board and with continuous passive motion machine.

Patients will be discharged from the hospital once they are fully mobilized and will be advised to do dynamic quadriceps exercise.

\section{Follow up}

The discharged patients were advised to report for follow up on every month, for 6 months, during each follow up the patients were examined for objective assessment including range of knee movement, extension lag, effusion, circumference of thigh, efficacy of quadriceps and questioned for subjective symptoms like pain, use of walking aid, giving away, stair case climbing, squatting which was recorded according to Modified Bostman scale ${ }^{[12]}$.

\section{Results}

Age

In this study age of patients was ranging from 19 yrs to $65 \mathrm{yrs}$ with median age of $39.5 \mathrm{yrs}(\mathrm{SD} \pm 12.607)$

\section{Gender}

In this study $70 \%$ were males and $30 \%$ were females.

\section{Side}

In this study the fracture over the right side was 14 (70\%) and left was $6(30 \%)$.

No bilateral fracture cases reported

\section{Mode and mechanism of injury}

In this study 12 cases were fall on knee and 7 were road traffic accident, 1 was direct trauma at work.

In this study $60 \%$ of fractures were due to indirect mechanism as in forceful flexion of the knee against the contracted quadriceps, and $35 \%$ were due to RTA and 5\% direct trauma to patella at work.

\section{Functional outcome}

In this study $10 \%$ had flexion $<90,10 \%$ were $90-120,80 \%$ more than 120 
In this study at the end of 6 months $70 \%$ had none or minimal pain, $20 \%$ had moderate on extension and $10 \%$ had during daily activities

The complications seen in our study 1 case $(5 \%)$ had superficial infection,

In this study 1 case $(5 \%)$ had proximal migration of the $\mathrm{k}$ wires.

\section{Score}

In our study according to modified bostman score 14 (70\%) cases were excellent, $4(20 \%)$ were good, $2(10 \%)$ were poor.

\section{Discussion \\ Age}

In this study age of patients was ranging from $19 \mathrm{yrs}$ to $65 \mathrm{yrs}$ with median age of 39.5 yrs $(\mathrm{SD} \pm 12.607)$ Sudheendra P.R, Krishna Prasad.S ${ }^{13}$ study shows youngest patient was of 21 years age and oldest was 62 years of age. Smith et al. ${ }^{[14]}$ mentioned the mean age as 48 years in their study.

\section{Gender}

In this study $70 \%$ were males and $30 \%$ were females. Anand. B. Jab Shetty ${ }^{[15]}$ out of 20 cases, there were 15 males (75\%) and 5 were females $(25 \%)$

\section{Side}

In this study the fracture over the right side was $14(70 \%)$ and left was $6(30 \%)$.

No bilateral fracture cases reported

Sudheendra P.R, Krishna Prasad.S [13]. study shows that patellar fractures occurred on right side in $60.5 \%$ cases while $39.5 \%$ occurred on left side.

\section{Mode and mechanism of injury}

In this study 12 cases were fall on knee and 7 were road traffic accident, 1 was direct trauma at work.

In this study $60 \%$ of fractures were due to indirect mechanism as in forceful flexion of the knee against the contracted quadriceps, and $35 \%$ were due to RTA and 5\% direct trauma to patella at work.

A.B.Jab Shetty ${ }^{[15]}$ stated that commonest mode of injury was fall on knee, which was seen in 12 cases i.e., $60 \%$ of cases and the rest $40 \%$ had road traffic accident.

In A.B.Jabshetty [15] study, patients with fractures of ipsilateral limb were excluded from the study.

\section{Functional outcome}

In this study $10 \%$ had flexion $<90,10 \%$ were $90-120,80 \%$ more than 120

Sudheendra P.R, Krishna Prasad.S ${ }^{[13]}$ mentioned only one patient having range of knee motion of less than 90 degrees and was associated with a poor outcome.

In our study extensor lag more than 5 recorded (using goniometer) in $20 \%$

Sudheendra P.R, Krishna Prasad.S ${ }^{[13]}$ recorded Extensor lag of 5 or more degrees in $10(23 \%)$ cases.

$20 \%$ of cases in the study by Shrinivas et al ${ }^{[16]}$.

Higher incidence of extensor lag in our series could be attributed due to associated fractures in two cases, and due to age (65years), weak quadriceps strength in 1 case and poor motivation and superficial infection in other case.

Quadriceps power was of grade $\mathrm{v}$ in $80 \%$ and grade 4 in remaining cases.

This compares favorably with the Alglietti and Buzzi [17] series who observed normal strengths in $72 \%$.
In this study at the end of 6 months $70 \%$ had none or minimal pain, $20 \%$ had moderate on extension and $10 \%$ had during daily activities.

Sudheendra P.R, Krishna Prasad.S ${ }^{[13]}$ accounted 74\% with none or minimal, and $10 \%$ with moderate, and 2 had preexisting patellofemoral $\mathrm{OA}$.

In contrast to this Aglitti and Blizzi has $79 \%$ with none or mild pain and $21 \%$ with moderate pain. This might be due to long duration of follow up (upto 18 months).

The complications seen in our study 1 case $(5 \%)$ had superficial infection, but in the study of Srinivas et al ${ }^{[16]}$, no infection was noted.

In this study 1 case $(5 \%)$ had proximal migration of the $\mathrm{k}$ wires.

John $\mathrm{J}$ et al ${ }^{[17]}$ study mentioned loosening of K-wires is considered the main complication of the modified K-wire band fixation of patella fracture.

Wang Chengxue et al ${ }^{[18]}$ recorded 5 out of (6.9\%)patients with the modified K-wire tension band were badly affected by skin irritation probably due to K-wire prominence and migration.

Marten.H.G. Heusinkveld ${ }^{[19]}$ et al (2013) study shows pain and irritation were most commonly present following this modality of treatment. Skin irritation, wire migration or Kwire loosening were observed.

\section{Score}

In our study according to modified bostman score $14(70 \%)$ cases were excellent, $4(20 \%)$ were good, $2(10 \%)$ were poor.

Attique Ur Rehman Qureshi ${ }^{[20]}$ recorded excellent results in $36.67 \%$ and $56.67 \%$ with good results,

Sudheendra P.R, Krishna Prasad.S ${ }^{[13]}$ recorded Excellent in $58 \%$ ( 25 cases), Good in 16\% ( 7 cases) Fair in 18.6 ( 8 cases) and Poor in $4.7 \%$ ( 2 cases)

Anand. B. Jab Shetty ${ }^{[15]}$ mentioned the cases treated with modified tension band wire, excellent to good results were seen in $90 \%$ of cases.

According to Shrinivas et al ${ }^{[16]} 80 \%$ of cases treated with modified tension band wiring shown to have excellent to good results and $20 \%$ shown poor results.

However only transverse fracture of patella was included in this study.

The study was limited due to less period of time, and a longer duration of follow-up may be necessary to determine the true incidence and impact of patello-femoral arthritis.

Schimitsch ${ }^{[21]}$ et al observed that open reduction and internal fixation of patella fractures restores excellent limb and health status.

\section{Summary}

- In this study 26-35 and 46-55 age groups incidence were more with the mean of 39.7 .

- In our study, male patients outnumbered the females by more than double.

- $\quad$ Right sided patellar fractures were predominant.

- All fractures selected were of transverse type.

- $10 \%$ of our patients had associated injury with extensor lag.

- Modification with longitudinal K-wires was the preferred tension band wiring technique.

- Longitudinal midline skin incisi8on was used in all cases.

- $70 \%$ of our patients had no pain or only mild pain.

- Only 4(20\%) of our patients had significant extensor lag.

- Nearly $80 \%$ our patients had normal quadriceps strength. 
- In our study, $90 \%>90$ of knee flexion.

- The fixation technique did not affect the function of walking.

- $\quad 70 \%$ cases were excellent and $20 \%$ were good.

\section{Conclusion}

The study was conducted on 20 fresh patellar fractures during September 2015 and February 2017 with age group varying from 16 to $60 y$ rstreated by modified tension band wiring technique.

In patella fractures the most significant effects are loss of continuity of extensor mechanism of the knee.

The study shows that treatment of patella fractures with modified tension band wiring is a definitive treatment with minimal complications and good functional outcome.

The surgery helps for early mobilization post operatively.

Modified tension band wiring technique, eventually results in a favorable outcome in terms of satisfactory return of knee function.

Early and continuous physiotherapy following the surgery is a paramount importance in determining the end results.

This study favours that modified tension band wiring is the better choice for treatment of patella fracture.

Table 1: Age distribution

\begin{tabular}{|c|c|c|}
\hline Age group (in years) & No of cases & Percent \\
\hline $16-25$ & 2 & $10 \%$ \\
\hline $26-35$ & 6 & $30 \%$ \\
\hline $36-45$ & 4 & $20 \%$ \\
\hline $46-55$ & 6 & $30 \%$ \\
\hline$>56$ & 2 & $10 \%$ \\
\hline Total & 20 & $100 \%$ \\
\hline
\end{tabular}

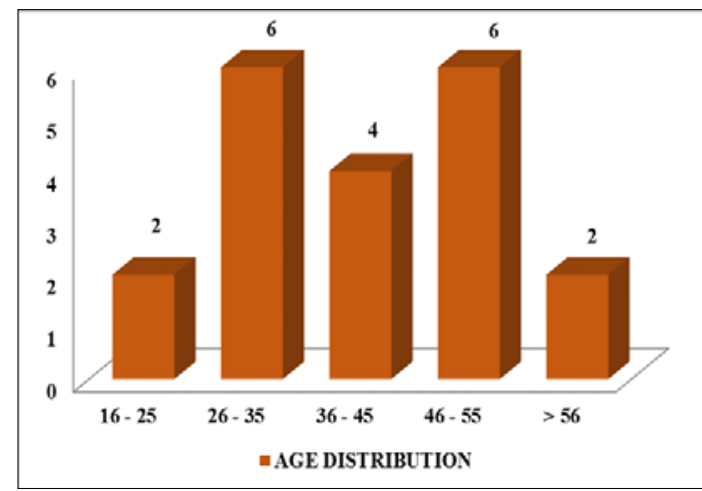

Mean Age $=39.7(\mathrm{SD} \pm 12.607)$

Table 2: Sex Incidence

\begin{tabular}{|c|c|c|}
\hline Sex & Distribution of cases & Percent \\
\hline Female & 6 & $30 \%$ \\
\hline Male & 14 & $70 \%$ \\
\hline Total & 20 & $100 \%$ \\
\hline
\end{tabular}

Table 3: side of fracture

\begin{tabular}{|c|c|c|}
\hline Side of fracture & No of cases & Percent \\
\hline Left & 6 & $30.00 \%$ \\
\hline Right & 14 & $70.00 \%$ \\
\hline Total & 20 & $100.00 \%$ \\
\hline
\end{tabular}

SIDE OF FRACTURE

LEFT $\square$ RIGHT

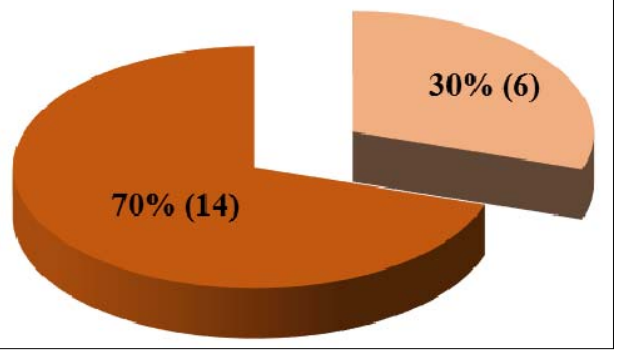

Table 4: mechanism of injury

\begin{tabular}{|c|c|c|}
\hline Mechanism of injury & No of cases & Percent \\
\hline Direct & 8 & $40.00 \%$ \\
\hline Indirect & 12 & $60.00 \%$ \\
\hline Total & 20 & $100.00 \%$ \\
\hline
\end{tabular}

\section{MECHANISM OF INJURY}

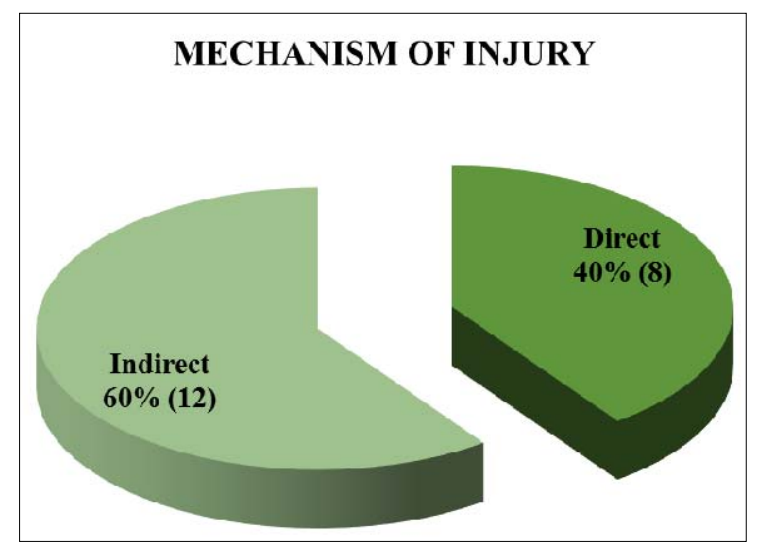

Table 5: type of fracture

\begin{tabular}{|c|c|c|}
\hline Type of fracture & No of cases & Percentage \\
\hline Open & 5 & $25 \%$ \\
\hline Closed & 15 & $75 \%$ \\
\hline Total & 20 & $100 \%$ \\
\hline
\end{tabular}

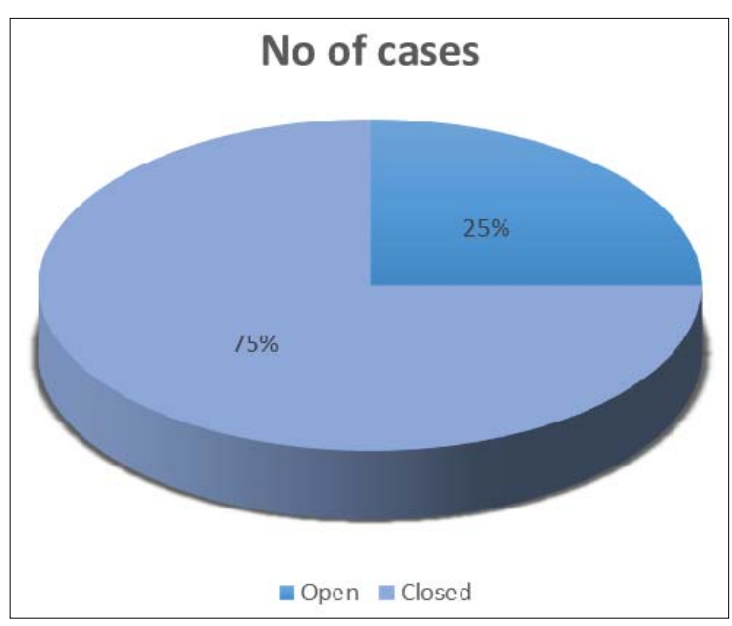


Table 6a: complications

\begin{tabular}{|c|c|c|}
\hline Complication & Cases & Percentage \\
\hline Present & 5 & $25 \%$ \\
\hline Not PRESENT & 15 & $75 \%$ \\
\hline Total & 20 & $100 \%$ \\
\hline
\end{tabular}

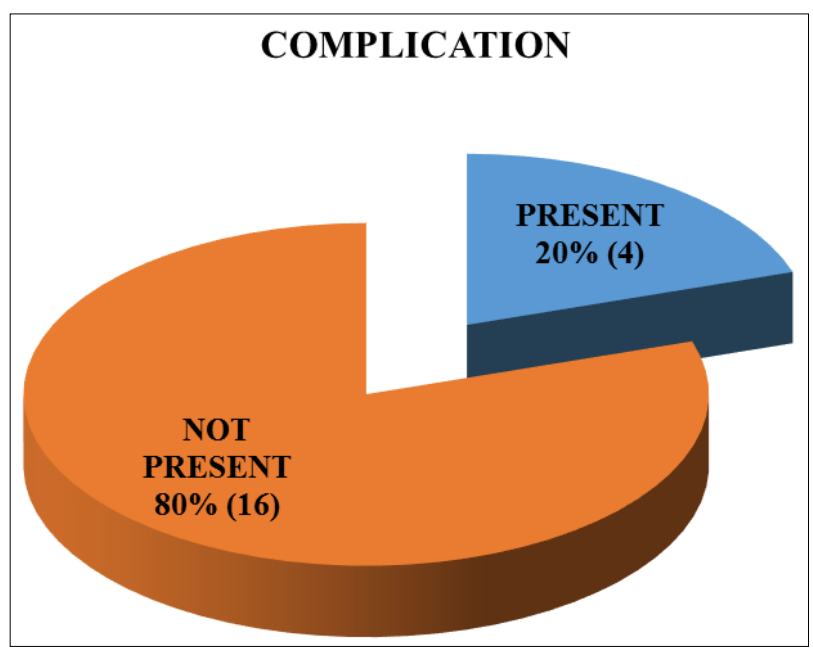

Table 6b: functional outcome

\begin{tabular}{|c|c|c|}
\hline Complications & Cases & Percentage \\
\hline $\begin{array}{c}\text { Proximal migration of k wire with loss } \\
\text { of complete flexion }\end{array}$ & 1 & $5 \%$ \\
\hline $\begin{array}{c}\text { Superficial wound infection with } \\
\text { extension lag }\end{array}$ & 1 & $5 \%$ \\
\hline Extension lag & 1 & $5 \%$ \\
\hline $\begin{array}{c}\text { Loss of complete flexion with extension } \\
\text { lag }\end{array}$ & 2 & $10 \%$ \\
\hline Mal union & 0 & $0 \%$ \\
\hline Non union & 0 & $0 \%$ \\
\hline No Complication & 15 & $75 \%$ \\
\hline Total & 20 & $100 \%$ \\
\hline
\end{tabular}

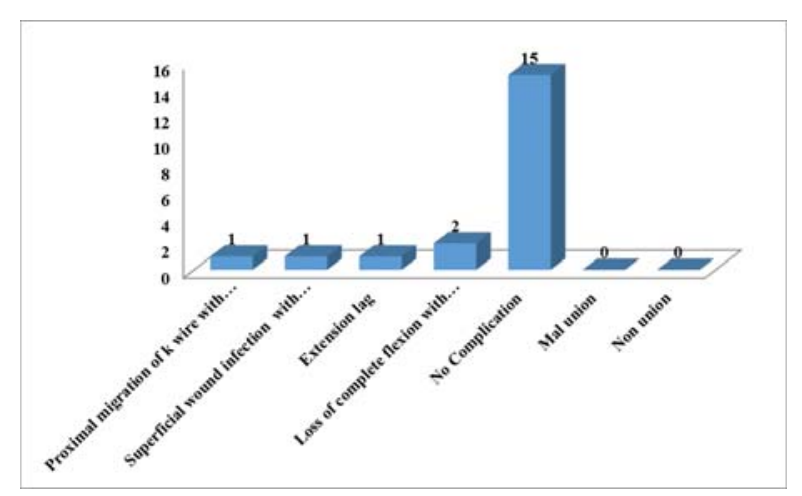

Table 7a: knee flexion

\begin{tabular}{|c|c|c|}
\hline Knee flexion (in degrees) & CASES & Percent \\
\hline$<90^{0}$ & 2 & $10 \%$ \\
\hline $90^{0}-120^{0}$ & 2 & $10 \%$ \\
\hline$>120^{0}$ & 16 & $80 \%$ \\
\hline Total & 20 & $100 \%$ \\
\hline
\end{tabular}

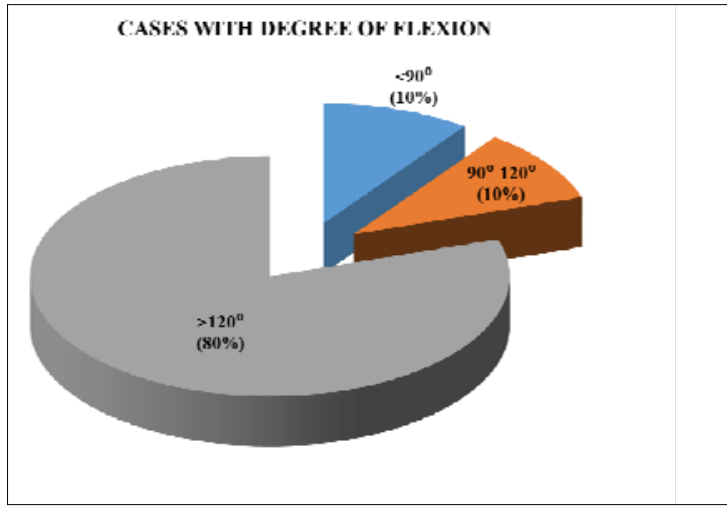

Table 7b: knee extensor lag

\begin{tabular}{|c|c|c|}
\hline Extensor lag (in degrees) & Cases & Percent \\
\hline 0 to $5^{0}$ & 16 & $80 \%$ \\
\hline $6^{0}-10^{0}$ & 3 & $15 \%$ \\
\hline $11^{0}-15^{0}$ & 1 & $5 \%$ \\
\hline Total & 20 & $100 \%$ \\
\hline
\end{tabular}

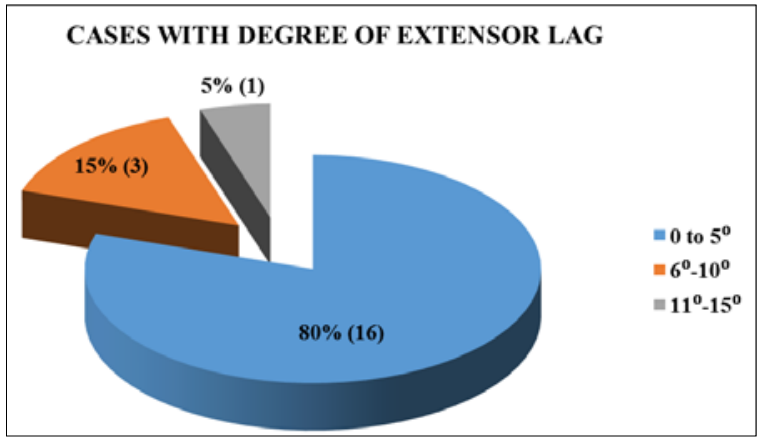

Table 8: results

\begin{tabular}{|c|c|c|}
\hline Results & Cases & Percentage \\
\hline Excellent & 14 & $70 \%$ \\
\hline Good & 4 & $20 \%$ \\
\hline Poor & 2 & $10 \%$ \\
\hline Total & 20 & $100 \%$ \\
\hline
\end{tabular}

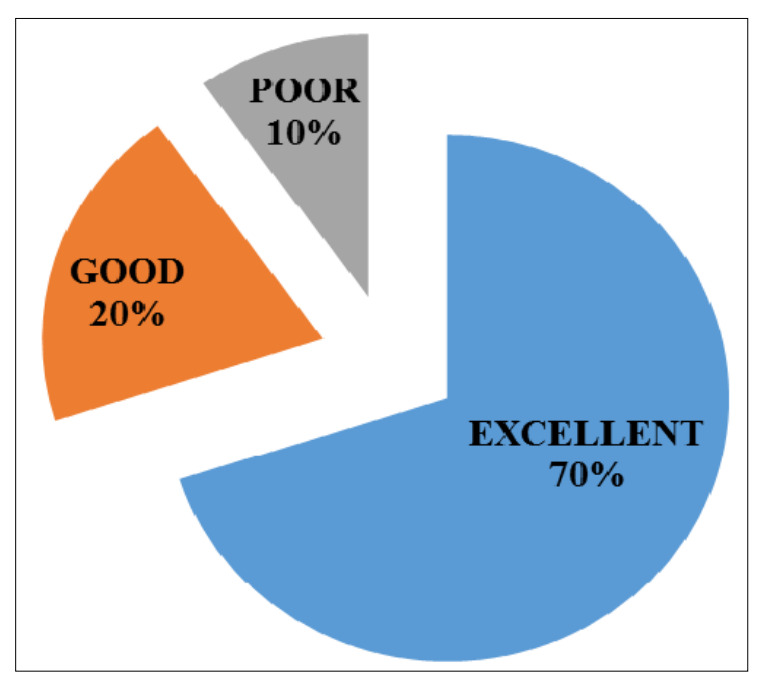


Case 6

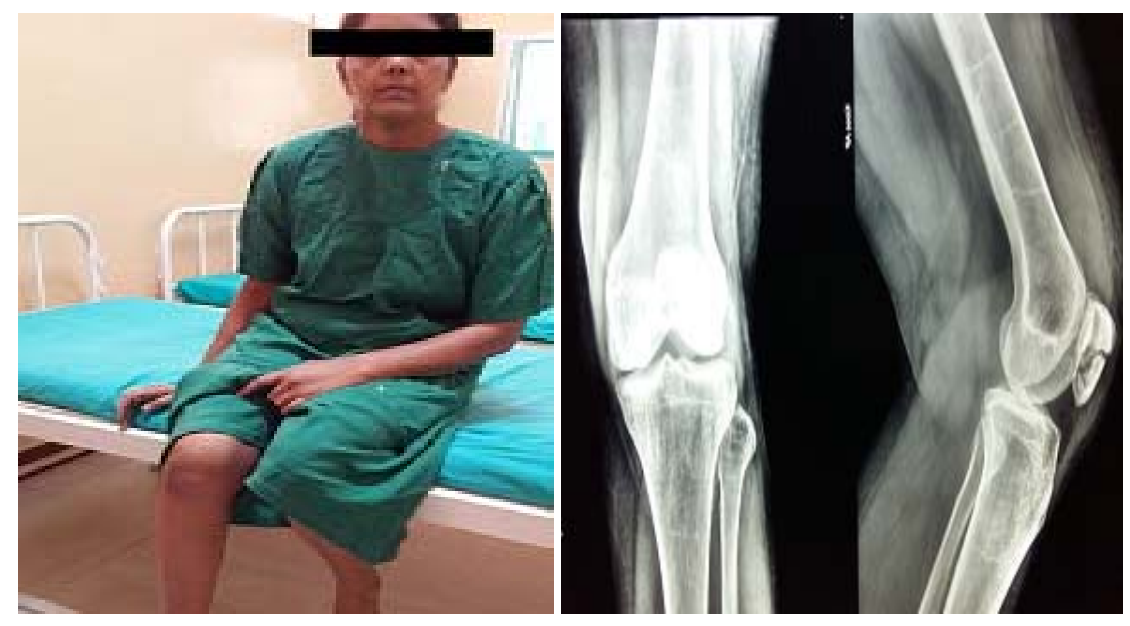

Fig 1 a

Fig 1 b

Pre operative

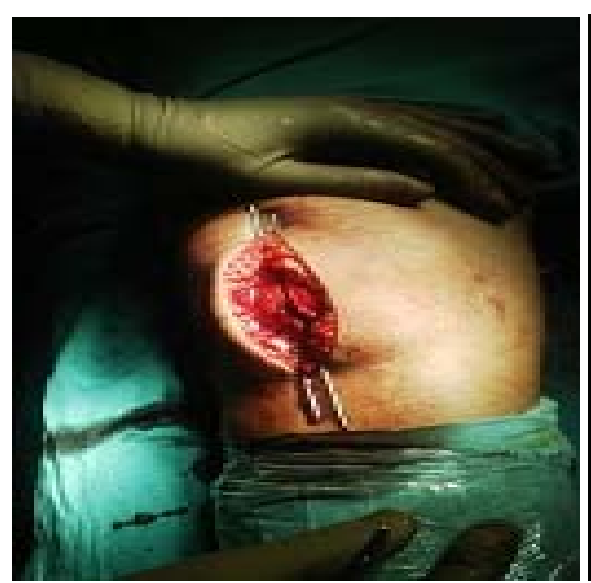

Fig 1 c

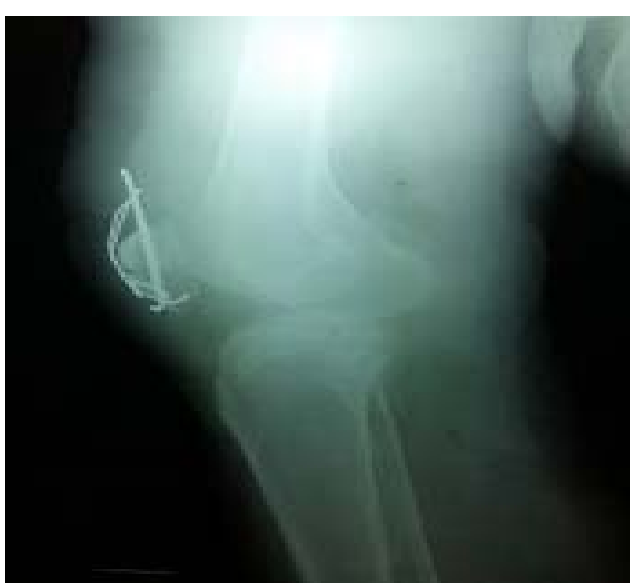

Fig $1 \mathrm{~d}$

immediate post operative

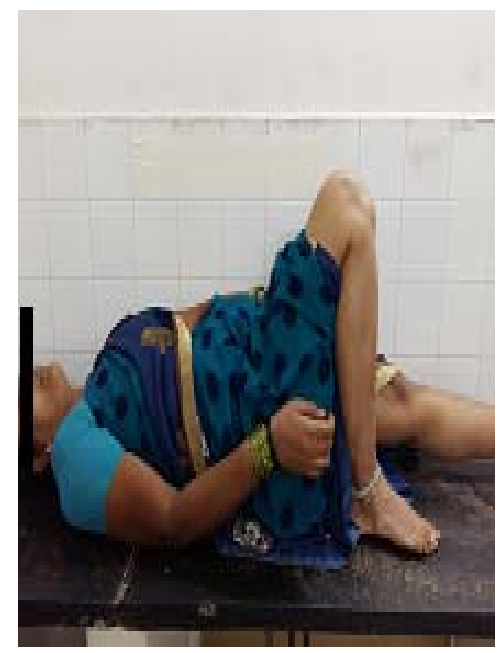

Fig 1 e

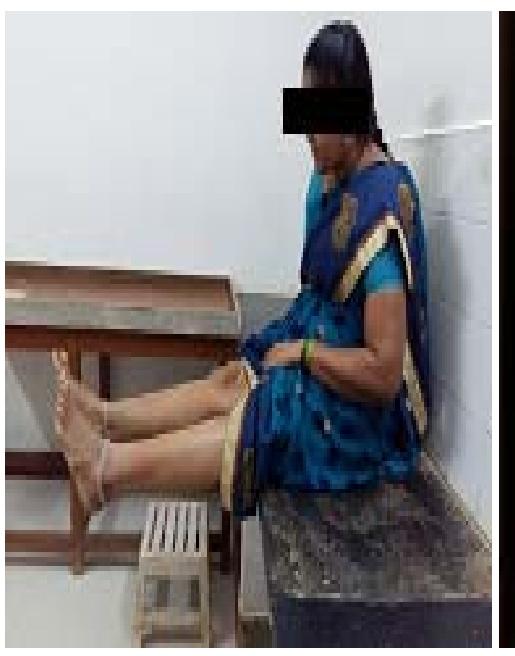

Fig $1 \mathrm{f}$

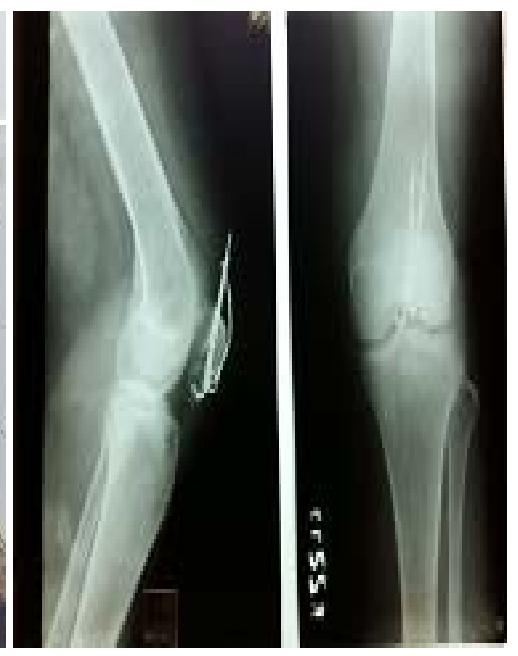

Fig 1 g

Final Follow UP 


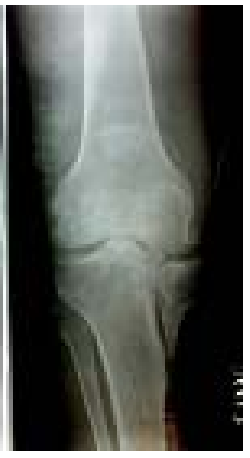

Pre- operative

Fig 2 a.

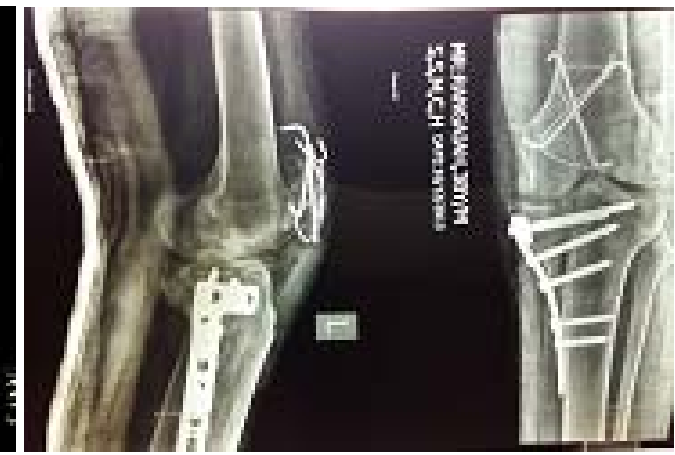

post - operative

Fig 2 b

\section{Follow up}

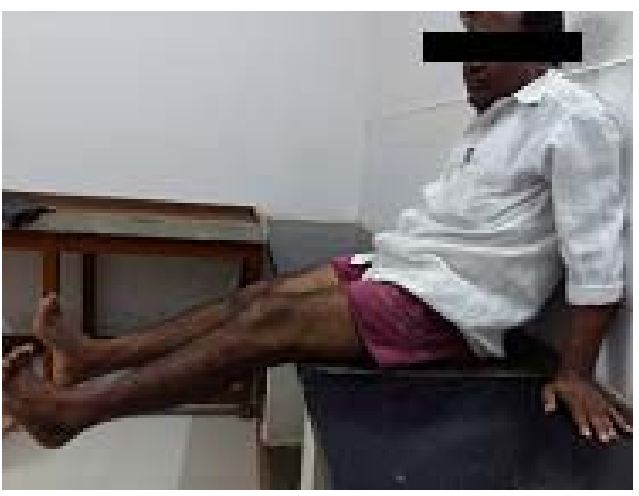

Fig 2 c

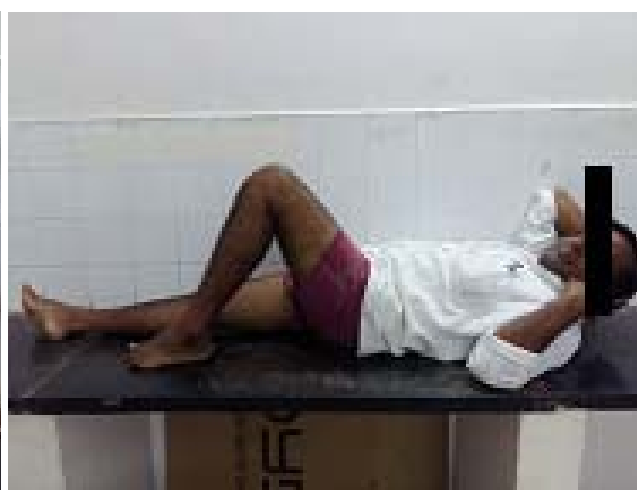

Fig 2 d

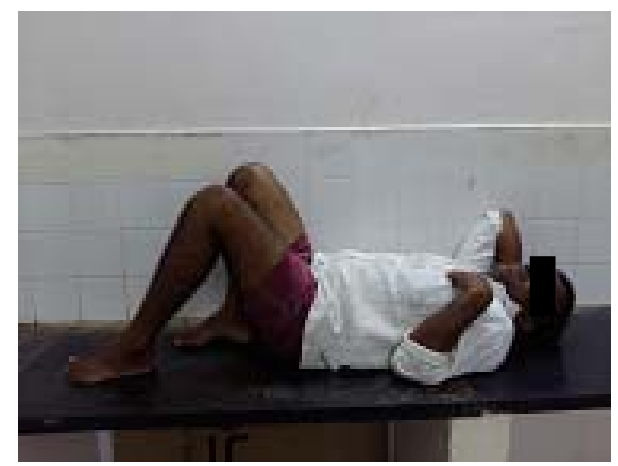

Fig 2 c: Final follow up - Extension lag and loss of complete flexion

Case 16

Superficial wound infection

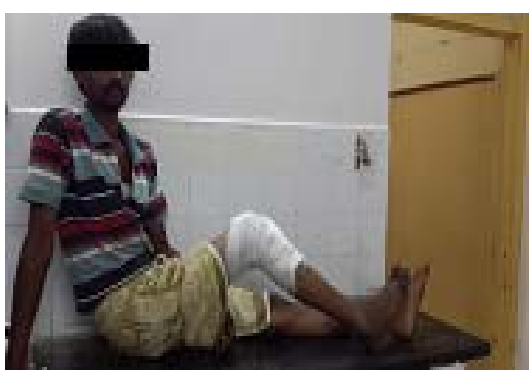

Fig 3 a

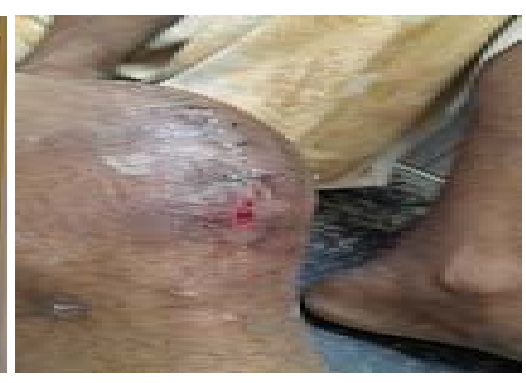

Fig 3 b 


\section{Acknowledgements}

We thank our colleagues from Sri Siddhartha Academy of Higher Education who provided insight and expertise that greatly assisted the research.

We thank faculty of Department of orthopaedics, Sri Siidhartha medical college, affiliated to Sri Siddhartha Academy of Higher Education for assistance and for comments that greatly improved the manuscript.

\section{Declarations}

Funding: none

Conflict of interest: none

Ethical approval: Approved by ethical committee

\section{References}

1. Campells operative orthopaedics. Chapter $54.12^{\text {th }}$ edition, Edt. S.Terry, James. H. Beaty. 2013; 3:2681-2688.

2. Charles Court-Brown M, James Heckman D, Margaret Mc Queen M, William Ricci M, Paul Tornetta III (eds). Rockwood and Green's Fractures in adults. Eighth edition: Wolters Kluwer, 2015.

3. Thompson JEM. Comminuted fractures of Patella JBJS (Am). 1935; 17:431-436.

4. Brooker R. Treatment of fracture patella by excision" a study of morphology of function. British Journal of.surgery. 1936; 37(24):733.

5. Grooves Hey EW. A note on the extension apparatus of the knee joint. British Journal of surgery. 1937; 24:747748.

6. Haxton HA. The functions of the patella and the effects of its excision. The Journal of surgery, gynecology and obstetrics. 1945; 80:389.

7. Cohn BNE. Total and partial patellectomy. Journal of surgery, gynecology and obstetrics. 1944; 79:526-526.

8. Scott JC. Fractures of the patella. JBJS: 1949, 31:76.

9. E1nolas S, AHO AJ, kallio P. Patellectomy after fracture. Acta. ortho Scand. 1967, 441-447.

10. MULLER ME et al. Manual of internal fixation, Technique recommended by the AO-ASIF group, 564568.

11. Maarten HG, Heusinkveld, Anniek den Hamer, Willeke A, Traa Pim JA. Oomen Nicola Maffulli. Treatment of transverse patellar fractures: a comparison between metallic and non-metallic implants. British Medical Bulletin. 2013; 107:69-8

12. Kaufer H. Mechanical of the patella. JBJS (Am). 1971; 53:1551.

13. Sudheendra Krishnaprasad PR. Functional outcome of patellar fractures treated by internal fixation: a retrospective study. Journal of Evolution of Medical and Dental Sciences. 2014; 3(29):8126-8141.

14. Grooves Hey EW. A note on the extension apparatus of the knee joint. British Journal of surgery. 1937; 24:747748.

15. Anand Jabshetty B. A comparative study of modified tension brand wiring and cerclage wiring in management of transverse fractures of patella. Indian Journal of Science and Technology. 2011; 4:0974-6846.

16. Shrinivas K, Suryaprakasrao V, Narendranath L, Prasadrao VBN. Evaluation of results of surgical treatment of closed fractures of patella. Indian J. Orthop. 2004; 38:104-106.

17. John J, Wagner WW, Kuiper JH. Tension-band wiring of transverse fractures of patella. The effect of site of wire twists and orientation of stainless steel wire loop: a biomechanical investigation ${ }^{[\mathrm{J}]}$. Int Orthop. 2007; 31(5):703-7.

18. Wang Chengxue, Tan Lei, Qi Baochang, Hou Xiangfeng, Huang Yulong, Zhang Haipeng et al. Chinese Journal of Traumatology. 2014; 17(4):208-213.

19. Maarten HG, Heusinkveld, Anniek den Hamer, Willeke A, Traa Pim JA et al. Treatment of transverse patellar fractures: a comparison between metallic and nonmetallic implants. British Medical Bulletin. 2013; 107:69-8.

20. Attique Ur Rehman Qureshi. Post-Operative Functional Outcome of Modified Tension Band Wiring in Patients with Transverse Fracture of Patella [internet]. DHQ Hospital, Bhakkar: Department of Orthopaedic Surgery; 2011 june [cited 2013]. available from: http://pjmhsonline.com

21. Bostman O, Kiviluoto O, Nirhamo J. Comminuted displaced fractures of the patella injury. British $\mathrm{J}$. Accident Surgery. 1981; 13(3):196-202. 